\title{
METHODS OF ASSESSING THERAPY IN CHOREA WITH SPECIAL REFERENCE TO THE USE OF A.C.T.H.
}

BY

\author{
A. ST.J. DIXON and E. G. L. BYWATERS \\ From the Special Unit for the Study and Care of Juvenile Rheumatism, Canadian Red Cross Memorial \\ Hospital, Taplow, Bucks.
}

(RECEIVED FOR PUBLICATION JULY 16, 1951)

Like other manifestations of the rheumatic state chorea is subject to spontaneous remissions and relapses which make the assessment of the action of any particular therapy notoriously difficult. Furthermore, objective measurements of the degree of chorea seem necessary to confirm clinical impressions of an increase or decrease of chorea. With this in mind certain objective methods of assessing the action of therapy in chorea have been worked out, and are presented together with some results of their application to the treatment of chorea with A.C.T.H. Treatment may alter the severity of the duration of chorea. Its severity has been estimated in three ways: first, by clinical grading, secondly, by dexterity tests, thirdly, by means of a kinetic bed. In addition, certain permanent records of the choreic state have been developed which facilitate subsequent assessment of changes.

\section{Clinical Grading}

The following clinical grades are based on daily observation, with special attention to movement of outstretched hands, steadiness of grip, speech and emotional lability:-Grade $0=$ no chorea; grade $1=$ just discernible chorea ; grade $2=$ all cases of chorea between grades 1 and 3 ; grade $3=$ severe chorea where the patient is crippled by involuntary movements and cooperates with difficulty or not at all in the writing and dexterity tests.

\section{Dexterity Tests}

A standard peg-board* with 100 small plastic pegs is used. The time taken by the patient to fit the pegs into the board is used as an index of the severity of chorea (Fig. 1). An arbitrary upper

- Obtainable from Dryad Handicrafts Ltd., 22 Bloomsbury Street, W.C.1. limit of normal of four minutes has been included in the diagrams.

\section{Kinetic Bed}

This instrument gives a semiquantitative record of the movements of a choreic child in bed. An elongated pneumatic rubber cushion, 6 in. wide : $3 \mathrm{ft}$. long, is placed transversely actoss the bed at the level of the elbows and upper lumbar vertebrae. The air in the cushion is connected by a rubber tube to a manometer and a rubber tambour. The cushion is inflated to a standard pressure (between 5 and $10 \mathrm{~cm}$. of water) with the child lying in bed. Movement of the child upon the cushion causes

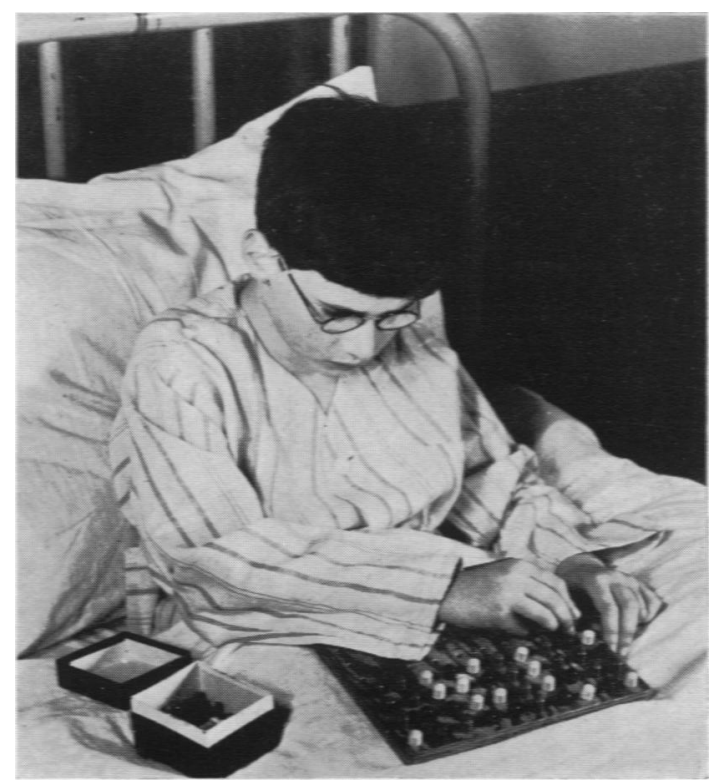

Fig. 1.-Patient doing dexterity test. 
changes in pressure in the tambour. The movements of the tambour (Fig. 2) rotate a wheel by a ratchet mechanism. To the wheel is attached a contact which once every complete rotation makes and breaks an electrical circuit to a counter. A special feature of this mechanism is the very small advance of the wheel with each step of the ratchet. The least change of pressure in the tambour which can be recorded will cause an advance of the wheel one hundredth of that caused by the largest change in pressure. Thus the instrument adds up not only the number but the force of the movements. The kinetic bed score is in arbitrary units, but an indication of its meaning is provided by some tests with a normal 10-year-old girl. In her, the following repeated movements caused a score of one unit on the kinetic bed: (1) one arm lifted and dropped49 times; (2) raising of body from hips up to a resting position on one elbow-20 times; (3) transfer of small article from locker to bed- 45 times; (4) lifting both hips to straighten nightdress -7 times.

The choreic child lies on the kinetic bed throughout the 24 hours. Readings are taken at 7 a.m. and 7 p.m. The day score is always larger than the night score, and both day and night scores may reach high figures in very choreic children; for example, one child caused a score of 300 (day) and 60 (night). Nonchoreic children, even if active in bed, rarely score more than 20 (day) and 5 (night). A representative arbitrary normal reading of 10 for the day score has been included in the diagrams.

\section{Permanent Records}

We have taken cine films of chorea and have recorded the choreic voice, but we have found that simpler tests give equally satisfactory results. One of these is a standard writing test, in which the patient signs her name and copies a simple design, and another is a 30-second exposure photograph of the choreic child with a flash lamp bulb attached to her finger which she attempts to keep still (Fig. 3).
TABLE 1

Analysis of Duration of Chorea in 90 Patient-Attacks*

\begin{tabular}{ccc|c}
\hline $\begin{array}{c}\text { Interval } \\
\text { after Onset } \\
\text { (weeks) }\end{array}$ & $\begin{array}{c}\text { Total (a) } \\
\text { Choreic at } \\
\text { Beginning of } \\
\text { Interval }\end{array}$ & $\begin{array}{c}\text { No. }(b) \\
\text { Losing } \\
\text { Chorea during } \\
\text { Interval }\end{array}$ & $\begin{array}{c}\text { Recovery } \\
\text { Rate } \\
(b / a \times 100) \\
\text { in Interval }\end{array}$ \\
\cline { 1 - 2 } $0-4$ & 90 & 7 & $7 \cdot 8$ \\
$4-8$ & 83 & 18 & $21 \cdot 7$ \\
$8-12$ & 65 & 14 & $21 \cdot 5$ \\
$12-16$ & 51 & 15 & $29 \cdot 5$ \\
$16-20$ & 36 & 7 & $19 \cdot 5$ \\
$20-24$ & 29 & 5 & $17 \cdot 3$ \\
$24-28$ & 24 & 4 & $16 \cdot 7$ \\
$28+$ & 20 & 20 & $100)$ \\
\hline
\end{tabular}

- Treatment by rest in bed only, apart from a few who received symptomatic treatment with sedatives or salicylates in small amounts.

\section{Duration of Chorea.}

This battery of tests can help in the evaluation of changes in severity of chorea under treatment, but improvement in the duration of chorea under treatment can only be assessed by comparison with the duration without treatment. Furthermore, the expected recovery rate varies with the previous

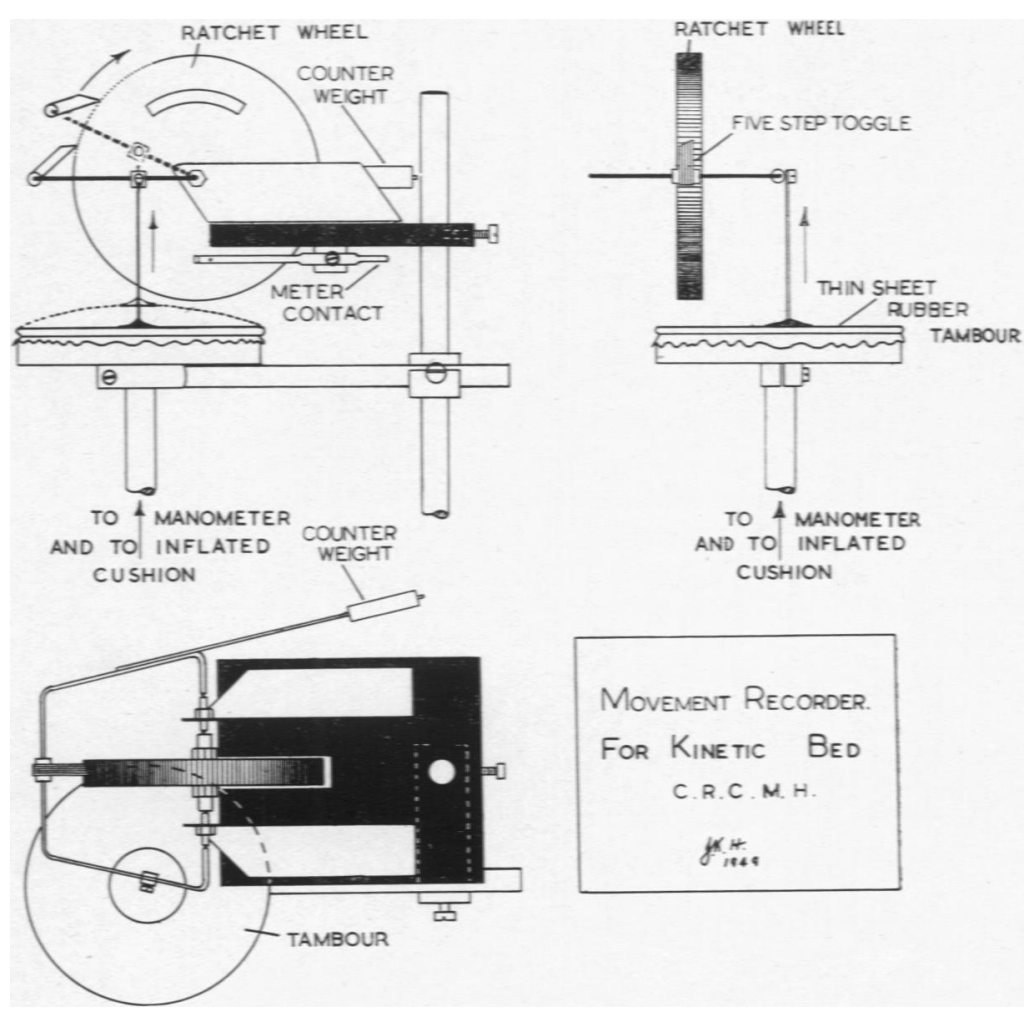

FK. 2.-Diagram of kinetic bed. 

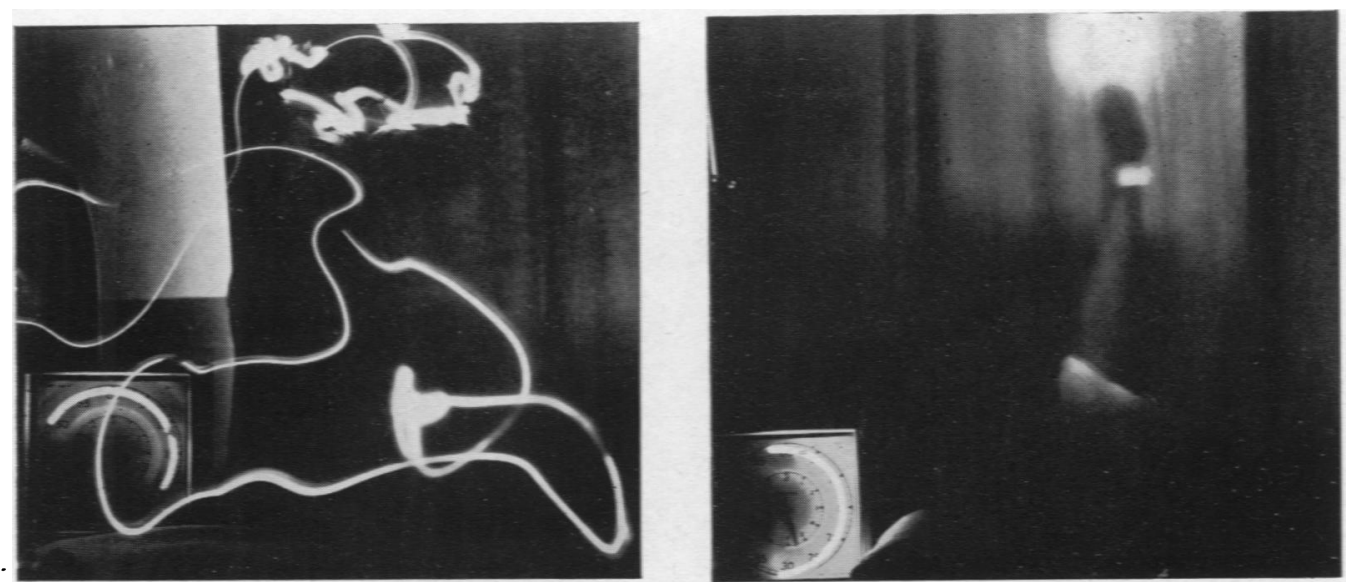

FK. 3.-Light-trace photograph of patient J.K. (30-second exposure) before and after spontaneous recovery in 14 days. A flash lamp bulb has been attached to the index finger. The patient is attempting to keep her finger still. The left-hand photograph shows grade III and the right hand one grade I chorea.

duration of the disease. We have, therefore, analysed 90 patient-attacks of chorea of which we have records of the dates of onset and of recovery, (Table 1) and have therefrom constructed a 'life table of the duration of the disease. It will be used for comparison with the recovery rate in a series of children receiving special treatment. This method is, of course, valid if there is no change in the nature of the disease.

Fig. 4 shows the recovery rate in four-week periods. For this series the expectation of recovery is least in the first month and greatest in the fourth, by the end of which period nearly two-thirds of the cases had recovered.

\section{Discussion}

Clinical grading is relatively simple, and after a little practice independent observers give the same grading. Grade 2, of course, embraces a wide range of severity of chorea, but this does-not matter in assessing therapy, since a drug is not likely to be of much use unless it can cause big changes in the patient's condition.

Dexterity test times are useful in the more severe cases, and follow clinical grading quite well. They

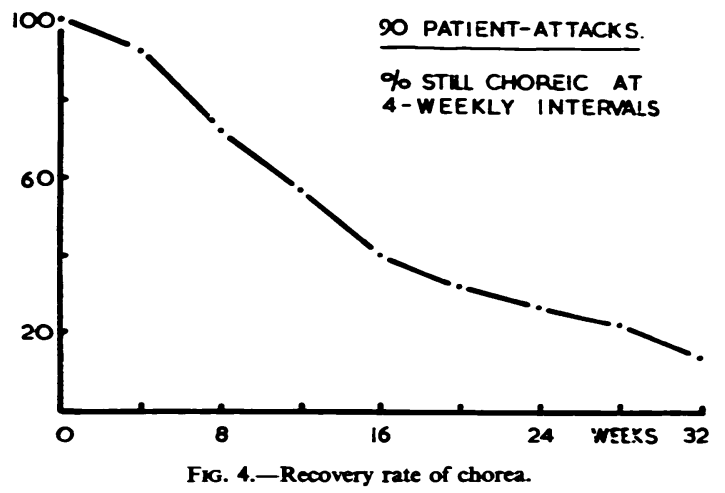

are increased by sedation. Because of the simplicity of this test the 'learning factor' can quickly be eliminated by one or two preliminary trials.

The kinetic bed score records all movements, both voluntary and choreic. The score varies with the grade of chorea (Fig. 5), but also with several other factors such as the inflation pressure of the bag, the age, body weight, alertness of the patient, the permitted activity of the patient and the

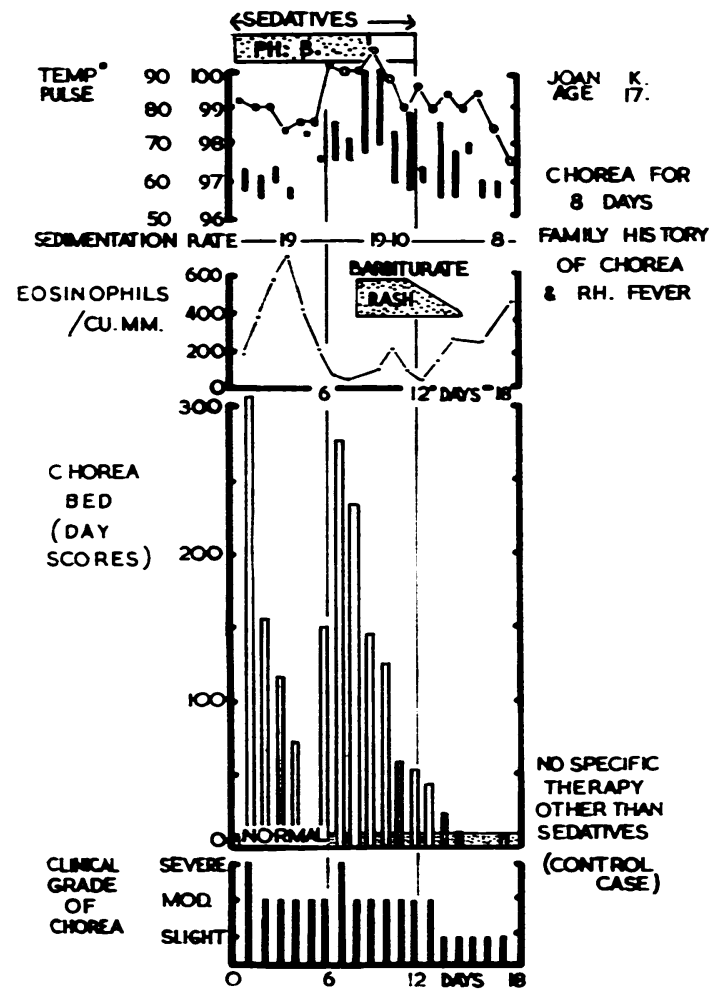

FiG. 5.-Chart of J.K. 


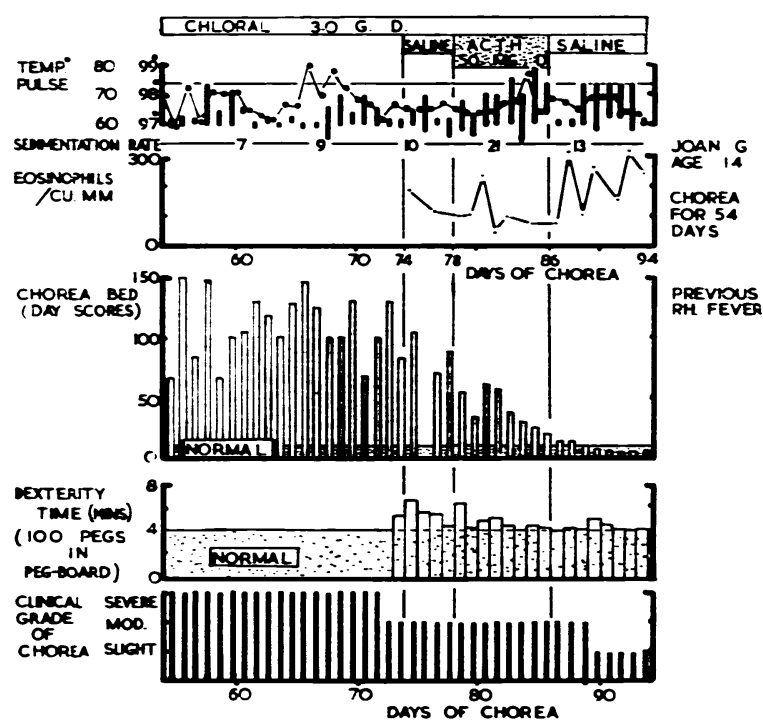

FiG. 6.-Chart of J.G.

amount of sedation. The kinetic bed has been used for comparing the same patient under standard conditions at different times, but not for comparing different patients; thus the day score in the same patient has varied from 300 to 10 during spontaneous recovery from severe chorea. 'Paralytic' chorea, and patients, such as M.B. (Fig. 9), who are severely ill, may give normal scores despite severe chorea. The principle of a recording bed has previously been used in connexion with schizophrenia (Gjessing, 1939).

The use of these tests has confirmed the existence of varying functional patterns of chorea. Thus in some patients there is little interference with voluntary movement, as shown by normal dexterity, but a great increase in movement at rest, as shown by the kinetic bed score (patient J.G.). On the other hand there may be gross interference with dexterity and little increase of movement at rest (patient D.B.).

\section{Results with A.C.T.H.}

This study was prompted by an early report (Massell, Warren, Sturgis, Hall and Craige, 1950) where it was mentioned that A.C.T.H. appeared to benefit a case of chorea, and by encouraging results from our own first case who recovered from severe chorea of 78 days' duration during an eight-day course of A.C.T.H. therapy. Since that time another favourable report has appeared (Bunim, 1951).

It is not possible to conclude that A.C.T.H. or



any other drug is the cause of a decrease in chorea, since chorea is a disease which can improve spontaneously, unless the natural recovery rate is significantly lower than the treated recovery rate under similar conditions. On the other hand, it is possible to conclude that A.C.T.H. does not benefit chorea if a small number of cases adequately treated do not respond. This has been found in the present small series.

Patients were selected who had severe or moderately severe chorea. During the study they were kept in bed in single-bed wards. Sedatives were avoided as far as possible. There was first a period, usually six days, in which control readings were made and saline injections given. A.C.T.H. was then substituted for saline. After six or eight days of A.C.T.H. saline injections were again given. These changes were made without the patient's knowledge. The degree of chorea was assessed as above, the effectiveness of the A.C.T.H. by daily direct eosinophil counts on capillary blood 
(Randolph, 1944) four hours after the first daily injection. All measurements were made at the same time of day. In some instances total urinary 17-ketosteroid excretion was followed.

\section{Case Reports}

Case 1. J.G., aged 14 (Fig. 6), suddenly developed a fourth attack of chorea on April 9, 1950. She showed severe chorea for 54 days before A.C.T.H. treatment was started, despite chloral hydrate sedation. She was emotional, dirty, disorientated and sometimes manic. A week before saline injections there was some improvement in her emotional state but no objective change. For four days saline injections were given. There was further slight improvement. During the next eight days she received A.C.T.H. (50 mg. day) and improved remarkably. When A.C.T.H. was stopped, improvement continued and there was no relapse. Chorea did not finally disappear until four weeks later. Our final impression was that we had treated this girl when she was recovering naturally.

Case 2. D.B., an intelligent girl of 14 (Fig. 7), had been previously admitted to this hospital for rheumatic fever and carditis, and was readmitted for severe chorea of three weeks' duration. She was given saline injections for six days. During this time her slightly raised temperature, pulse and sedimentation rates fell to normal, her kinetic bed score was moderately raised, and her chorea, which was severe, showed a gross interference

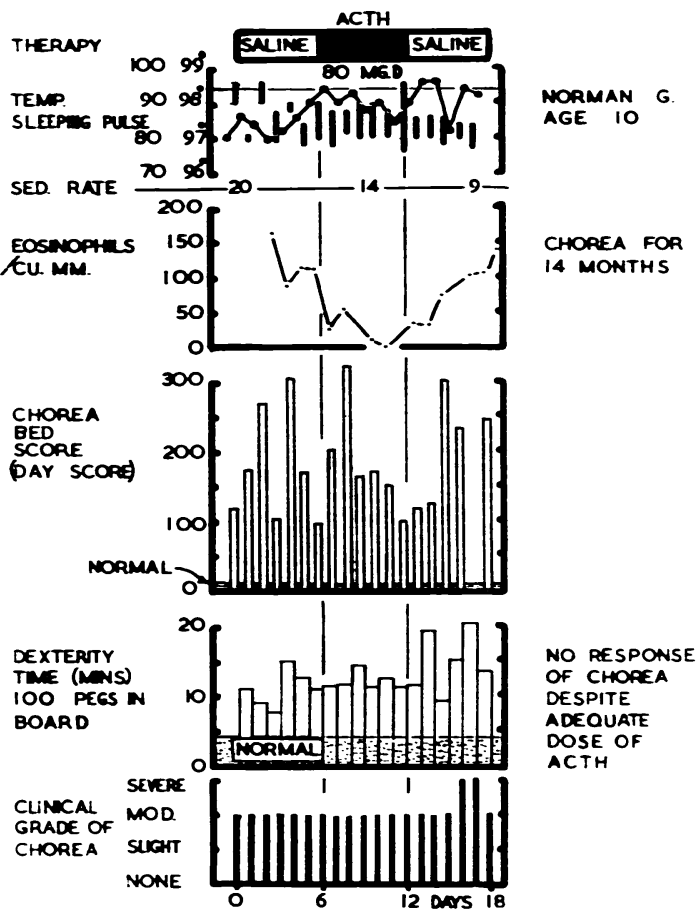

Fig. 8.-Chart of N.G. (Case 3).

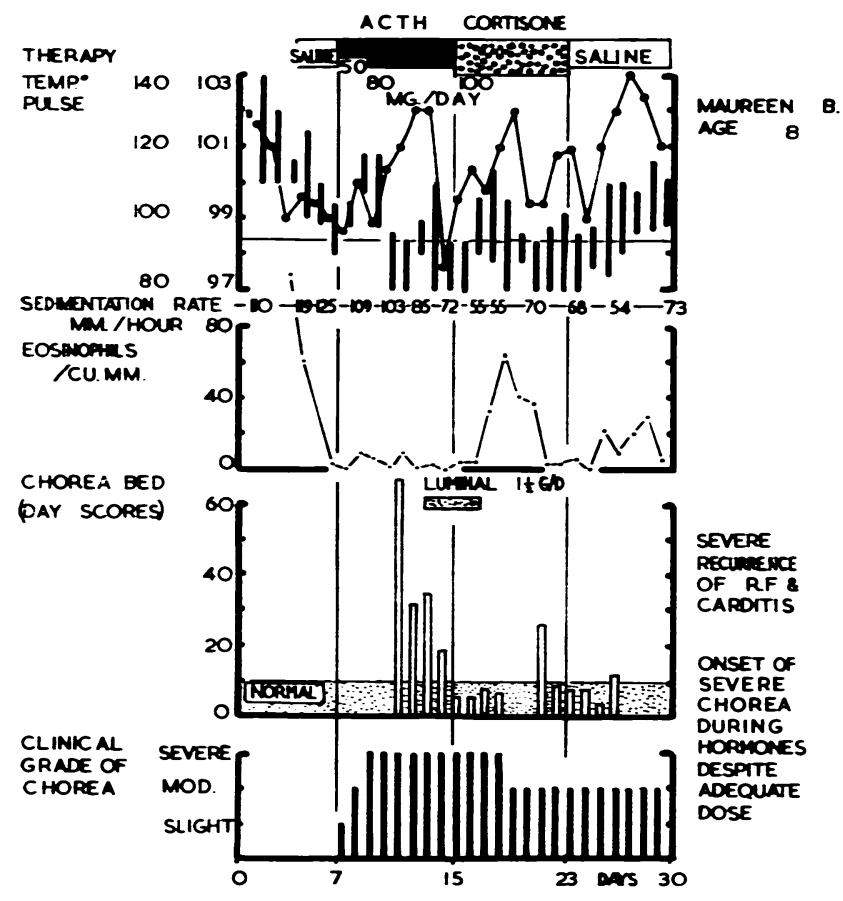

Fig. 9.-Chart of M.B. (Case 4). with attempted voluntary movement in the dexterity test. She could just write a recognizable signature. She was not emotionally disturbed. For the next three days she received A.C.T.H. (60 mg. daily), followed by three days at $120 \mathrm{mg}$. day. There was no improvement: on the contrary movements were so choreic that she was unable to hold a pencil to sign her name, and took up to $\mathbf{3 0}$ minutes to complete a dexterity test. Kinetic bed scores remained raised. At the same time, a low circulating eosinophil count showed that the dose was adequate.

During the next six days with saline injections there was little clinical change although kinetic bed scores and dexterity test times improved a little. Chorea began to improve in the following week and finally stopped in six weeks.

Case 3. N.G., a boy of 10 (Fig. 8), had had grade 1 chorea for 14 months, which relapsed to grade 2 while he was in hospital. He was followed in a similar way to Case 2 and showed much the same results. Despite a satisfactory fall in circulating eosinophils during A.C.T.H. treatment, there was no improvement in the clinical grade, dexterity or kinetic bed scores. He still shows grade 2 chorea five weeks after A.C.T.H. treatment. 


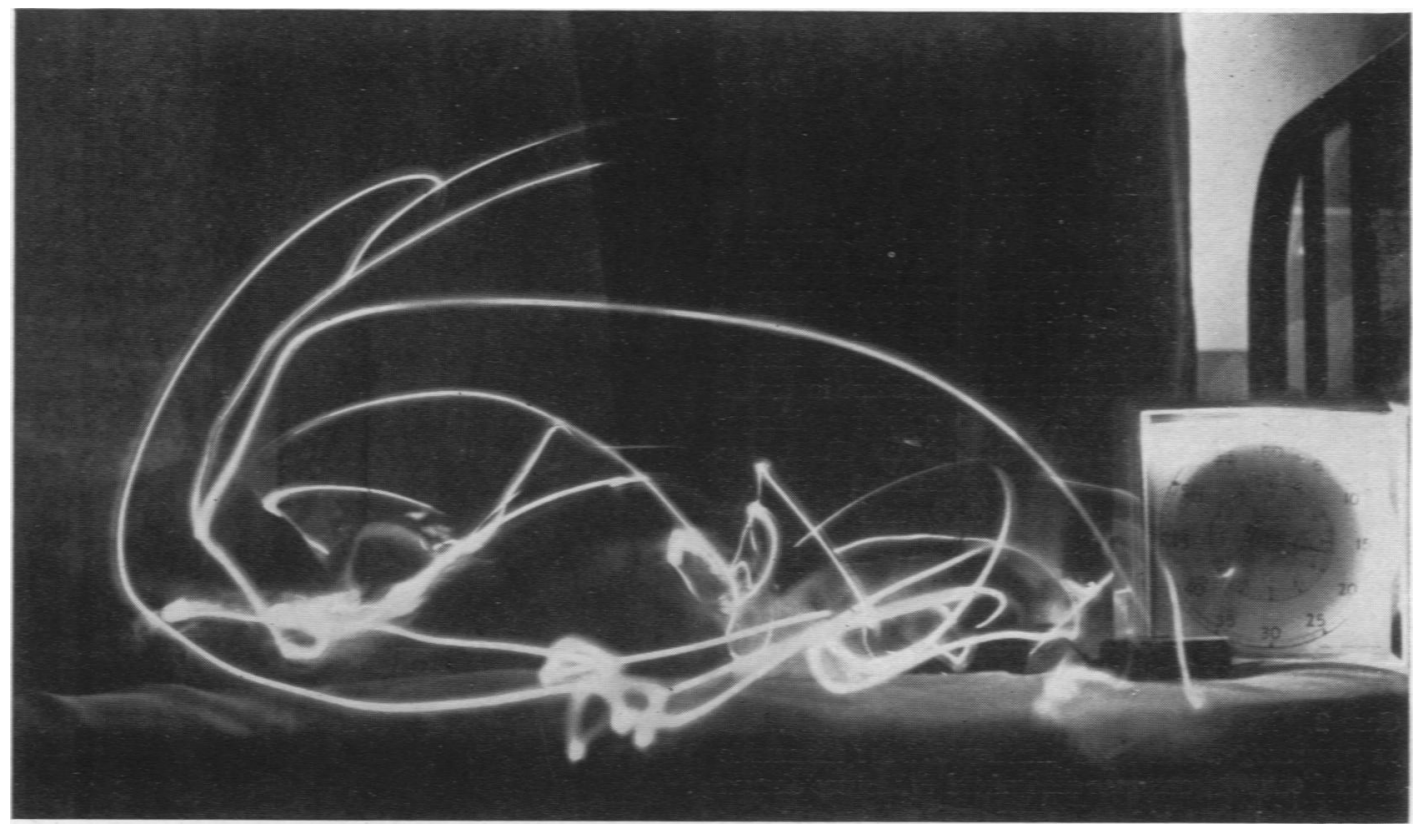

FIG. 10.-Chorea trace photograph of M.B. demonstrating grade III chorea at eighth day of A.C.T.H. therapy.

Case 4. M.B., aged 8 (Fig. 9) was admitted to this hospital with a recurrence of rheumatic fever and carditis. She was severely ill and developed pericardial and pleural effusions and congestive cardiac failure. The sedimentation rate was $110 \mathrm{~mm}$. in one hour (Westergren). There was no chorea. She was given $50 \mathrm{mg}$. A.C.T.H. daily from the seventh day of admission. This dose did not control fever and after three days was increased to $80 \mathrm{mg}$. daily for five days. Chorea first appeared on the evening of the first day of A.C.T.H. therapy and increased rapidly in severity. Luminal, gr. $1 \frac{1}{2}$ daily, was given from the sixth day of A.C.T.H. for four days. She was next given cortisone, $100 \mathrm{mg}$. daily, for eight days. There was only slight improvement in chorea. That doses of these hormones were adequate was shown by the falls in temperature and sedimentation rate. The eosinophil count had already fallen to a low level from heart failure before treatment. This low level was maintained throughout treatment, apart from a transient ' release rise' when cortisone was substituted for A.C.T.H. The kinetic bed score was not reliable because she was so weak and ill that her movements, although frequent, were too feeble to cause much change in pressure in the inflated rubber cushion on which she was lying. The true state of her chorea is shown more clearly by the 30-second photograph (Fig. 10) taken on the last day of A.C.T.H. treatment. The total duration of chorea in this girl was 13 weeks.

\section{Summary and Conclusion}

Methods of assessing the effects of therapy on the severity and duration of chorea are presented. A.C.T.H. treatment has been followed by these methods in four patients. The doses used were as great as, or greater than, those which in our hands previously had produced rapid improvement in other manifestations of the rheumatic state. A.C.T.H. in this dosage does not benefit Sydenham's chorea.

Acknowledgement and thanks are due to various colleagues, especially Mr. John Harrison who designed and constructed the ' kinetic bed' counter, and to $\mathrm{Mr}$. Peter Fiske, A.R.P.S., who took the photographs. The A.C.T.H. used was allocated by the M.R.C. Clinical Trials Committee from a gift made by Messrs. Armour Brothers Ltd., Chicago, Illinois.

\section{REFERENCES}

Bunim, J. J. (1951). Bull. N.Y. Acad. Med., 27, 75.

Gjessing, R. (1939). Arch. Psychiat. Nervenkr., 109, 326, 525 .

Massell, B. F., Warren, J. E., Sturgis, G. P., Hall, B. and Craige, E. (1950). New Engl. J. Med., 242, $641,692$.

Randolph, T. G. (1944). J. Allergy, 15, 89. 